\title{
New challenges for the Canadian Thoracic Society
}

\author{
Louis-Philippe Boulet MD, President, Canadian Thoracic Society
}

$I^{\prime}$ have been thinking for a while about what I would write in this editorial when I became president of the Canadian Thoracic Society (CTS). I found that it was really an opportunity, although a demanding task to take this position in the year 2000 in a rapidly changing world that is not short of new but exciting challenges. The marked progress in communications, the increased public awareness of respiratory health and environmental issues, the development of new technologies, changes in traditional ways to support research and the increasing demand on practitioners to acquire new knowledge and abilities makes it an unprecedented environment that asks us to rethink the way we used to do research and practice medicine.

Many of these issues will deeply influence CTS activities. For example, new developments in research funding in Canada, with the establishment of the Canadian Institutes for Health Research (CIHR), will widen the scope of our traditional mechanisms to support research. In this regard, our past President, Dr Malcolm King, should be thanked for all of his work with the society, particularly regarding his commitment to ensure that our respiratory community will have the place it deserves in the new CIHR. I am very pleased that he has agreed to pursue his work on this important development.

There is certainly a need to foster collaboration and joint initiatives among Canadian researchers in respiratory health, especially regarding clinical research, and the CIHR offers a particular opportunity for this. The development of a CTS clinical trials group to bring forward original ideas from our clinical researchers could also help to increase both collaboration and funding of Canadian-initiated research. Not only should there exist collaboration in initiation and performance of research, but collaboration in the evaluation of research activities should also be supported. Initiatives such as the national review program of provincial operating grants, coordinated by Dr Peter Paré, should continue. A search for partners to provide new fellowships will also help to increase funds available for our young researchers.

The CTS has been at the forefront of the development of practice guidelines for respiratory diseases.

These may be useful to the practitioner and other health care providers for offering optimal care. Dissemination of the asthma guidelines is presently ongoing, thanks to the hard work of Mr Michael McDonald and Dr Dennis Bowie, and such initiatives may be planned for other sectors of the respiratory field in the near future. Another aspect to ensuring optimal medical practices is the development of medical workshops, in collaboration with university-based continuing medical education (CME) offices, and other maintenance of certification (MAINCERT) initiatives, such as those suggested by the education committee, chaired by Dr Gordon Ford. Furthermore, I would like to underline the superb work done by Dr Sharon Peters in regard to the MAINCERT program.

Diffusion of information gathered from health research should be another duty of the CTS, in collaboration with the Canadian Lung Association (CLA). This should be done for the medical and scientific community, but also for those suffering from respiratory diseases and the general public. The Canadian Respiratory Journal, under the leadership of its 
editor Dr Norman Jones, contributes actively to this task and although still young, has already a most interesting track record regarding the quality of its publications. We should all be promoters of the Journal and regularly submit original research work, proceedings and other types of publications, to support our Journal.

I had the pleasure to enter into office during the joint meeting of the American and Canadian Thoracic Societies in Toronto, May 5 to 10. Needless to say, I was proud of the Canadian participation in this meeting, with well more than 500 presentations of original work (of a total of 5258), and a number of Canadians speaking or chairing many of the 40 symposia and 72 seminars. This year's conference, held for the first time in many years in Canada, was developed cooperatively by both the CTS and the American Thoracic Society (ATS), and some elements of the program were specifically an initiative of CTS members or other Canadian associations, such as the joint symposia on asthma education certification, tuberculosis control in the next millenium and hereditary telangiectasia. In this regard, I would particularly like to thank Dr Helen Ramsdale and Ms Valoree McKay for their commitment to this activity. Not only have Canadian scientists provided a significant contribution to the meeting regarding the number of works submitted, but also in their quality as well. For example, the collaborative work of the Quebec Research Network was selected as being of particular interest to the medical and scientific community and was exposed for the duration of the meeting. Substantial contributions from Canadian researchers were made in fields such as asthma, chronic obstructive pulmonary disease, respiratory infections, sleep apnea, critical care and many others, both in the basic and clinical sciences.

This year's Christie Memorial Lecture was given by Dr Clarence Guenter, who is the only person to have been president of both the CTS (1980) and ATS (1985). His thoughtful lecture was a wonderful journey through the evolution of modern medicine and was incisive and critical; I wish we more often had this kind of presentation, which changes our usual perspective on the evolution of medicine and current health care.

At the international conference, I had the chance to prepare some talks for the ATS, to review the past achievements and goals of our association. Although the CTS was officially established in 1958, medical and scientific activities in respiratory health have been going on since the development of the CLA, one hundred years ago. Our members have the role of advising the lung association on scientific matters and programs, including policies regarding support for research and professional education. When I reviewed these tasks and objectives, I realized that some were well fulfilled, but that others needed to be improved or reconsidered.

Finally, respiratory diseases are among the most important ailments in our society. The quality of air and smoking should be of particular concern. The public and government should realize that an active Canadian research program, through promotion of optimal care and high-quality patient education, can markedly change the morbidity and mortality caused by these frequent conditions.

To do so, however, we need both public and government support and all of us should not miss an opportunity to make this point and be active lobbyists to ensure adequate support in these initiatives. A strong scientific community, highquality respiratory care and a well-informed public will undoubtedly improve the quality of life of our population.

The CTS has an important role to play to improve the health of our fellow Canadians and contribute to the international effort to decrease the burden of respiratory diseases. Each one of us should ask, to paraphrase a most famous citation: 'Ask what you can do for your society, and not what your society can do for you'. In doing so, we will not only be able to maintain the high standards of respiratory medicine in the country, but we will improve our performance further, to the benefit of all those still suffering from lung diseases. 


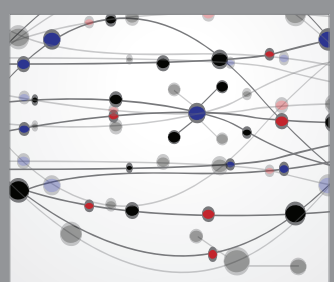

The Scientific World Journal
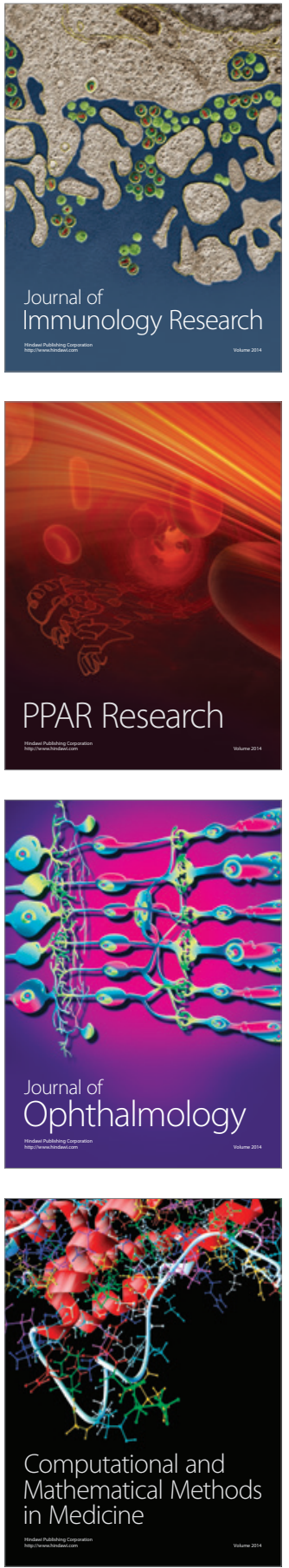

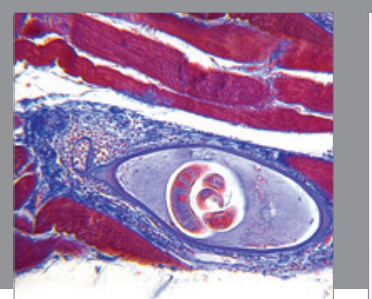

Gastroenterology Research and Practice

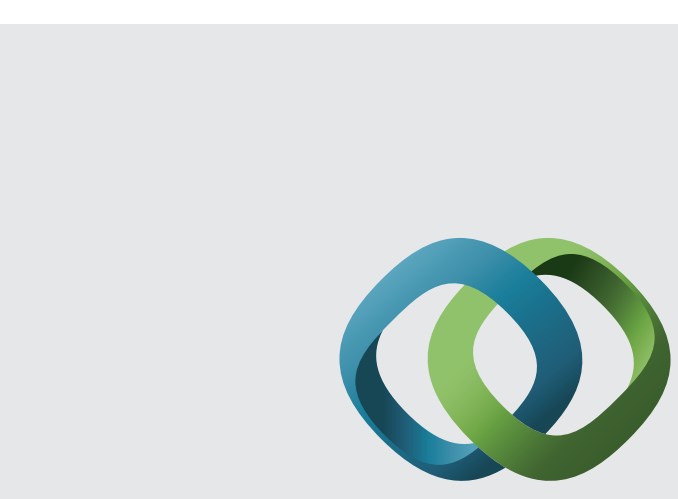

\section{Hindawi}

Submit your manuscripts at

http://www.hindawi.com
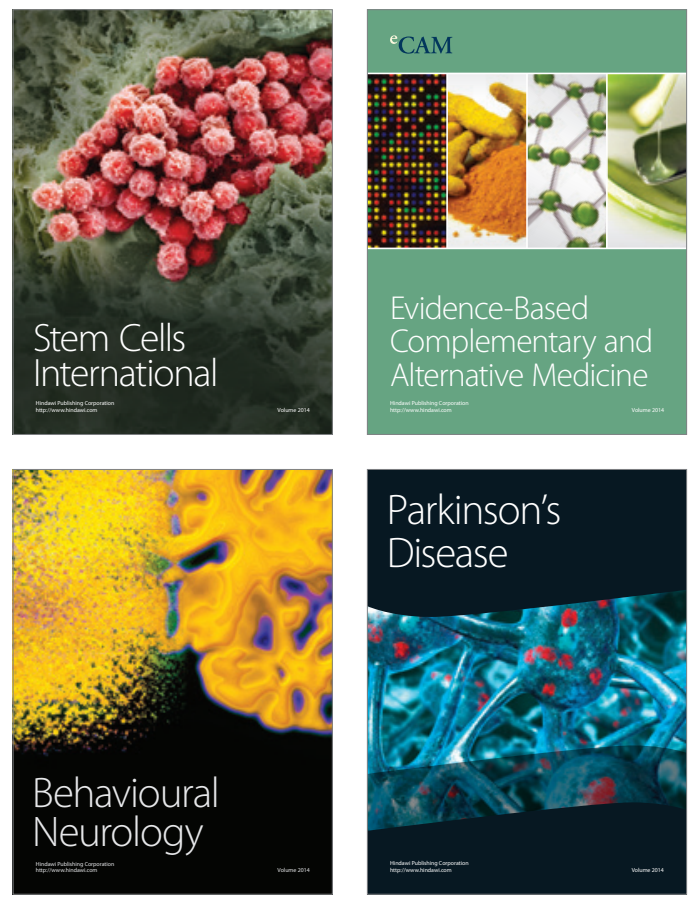
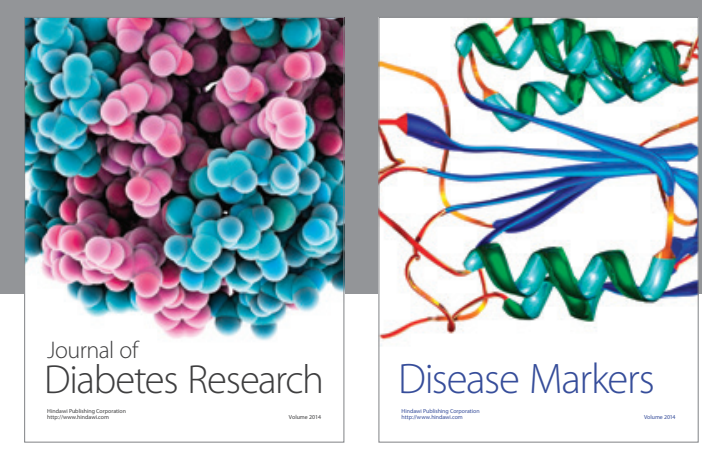

Disease Markers
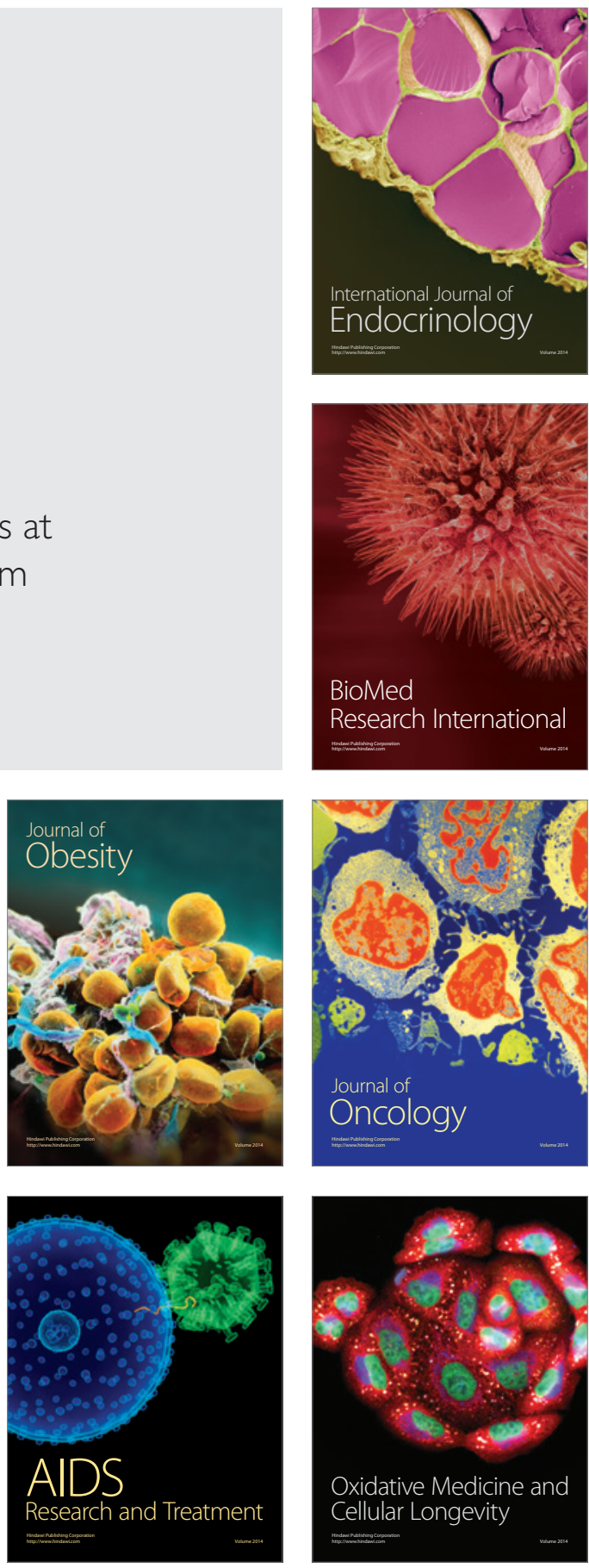